\title{
Morphological evaluation of atrioventricular septal defects by magnetic resonance imaging
}

J M Parsons, E J Baker, R H Anderson, E J Ladusans, Alison Hayes, S A Qureshi, P B Deverall, Nuala Fagg, A Cook, M N Maisey, M Tynan

\begin{abstract}
Twelve patients aged between 2 weeks and 22 months (median 6 weeks) with atrioventricular septal defects were examined with a $1.5 \mathrm{~T}$, whole body, magnetic resonance imaging system. Ten patients had a common atrioventricular orifice (complete defect) while two patients had separate right and left valve orifices (partial defect). Associated cardiac malformations included the tetralogy of Fallot in two, isomerism of the right atrial appendages and pulmonary atresia in two, and right isomerism and double outlet right ventricle in one. All had previously been examined by cross sectional echocardiography. Eight subsequently had angiography and six underwent surgical correction. There was one operative death and three other deaths. Three of these patients underwent postmortem examinations. Small children and infants were scanned inside a $32 \mathrm{~cm}$ diameter head coil. Multiple electrocardiographically gated sections 5 mm thick, separated by $0.5 \mathrm{~mm}$, were acquired using a spin echo sequence with echo time of $30 \mathrm{~ms}$. A combination of standard and oblique imaging planes was used. Magnetic resonance imaging was more accurate than echocardiography in predicting the size of the ventricular component of the defect. It was also better than either echocardiography and angiography in identifying the presence of ventricular hypoplasia. All these findings were confirmed by surgical or postmortem examinations or both.
\end{abstract}

Magnetic resonance imaging is capable of providing detailed morphological information in children with atrioventricular septal defects which is likely to be of value in their management.

Atrioventricular septal defects encompass a group of lesions associated with an underlying abnormality of the atrioventricular junction. These include a defect at the anticipated site of the muscular and atrioventricular septal structures of the normally septated heart. As there is no contiguity between atrial and ventricular septal structures, a common atrioventricular junction is present. There is basically a common atrioventricular valve with an abnormal arrangement of its valvar leaflets. Considerable variation occurs within this group of abnormalities. In particular, ventricular dominance of either the morphologically left or right ventricle may be present in association with hypoplasia of the opposite ventricle. Furthermore, there is a frequent association with other cardiac malformations. ${ }^{1}$ In each case, these anatomical features will be fundamental in determining prognosis. $^{2}$ It follows that a comprehensive evaluation of the cardiac anatomy is crucial in managing patients with this malformation. Cross sectional echocardiography is the major non-invasive method used to demonstrate this anatomy and often it is the only technique used before surgery. ${ }^{3}$ Invasive studies, however, are required when echocardiography fails to define the anatomy adequately.

Magnetic resonance imaging is a noninvasive technique capable of producing high resolution images of intracardiac anatomy in infants and children with congenital heart disease. ${ }^{4-6}$ One of its major strengths is the ability to acquire images in any plane. Imaging protocols can be adapted to suit the anatomy of individual patients. This makes it particularly valuable for studying malformations such as atrioventricular septal defects, where there may be considerable morphological variation. With these considerations in mind, we studied the ability of magnetic resonance imaging to provide an accurate morphological assessment of the cardiac abnormalities associated with atrioventricular septal defects, noting particularly those features of surgical importance.

\section{Patients and methods \\ PATIENTS}

Between March 1988 and March 1989 all new patients seen at Guy's Hospital with a diagnosis of atrioventricular septal defect, confirmed by cross sectional echocardiography, were invited to enter the study. Informed consent was first obtained from parents or guardians of the children and infants. Only the parents of one child declined and twelve patients were examined. The median age of the group was 6 weeks (range 2 weeks to 22 months). Seven patients had Down syndrome. Associated malformations included the tetralogy of Fallot in two patients, isomerism of the right atrial appendages with pulmonary atresia in two patients, and right isomerism with double outlet right ventricle and hypoplastic pulmonary arteries in one patient. After magnetic resonance imaging, eight patients underwent angiography. Six of these have since undergone 


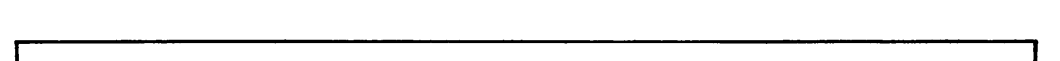

\section{Oblique imaging planes}
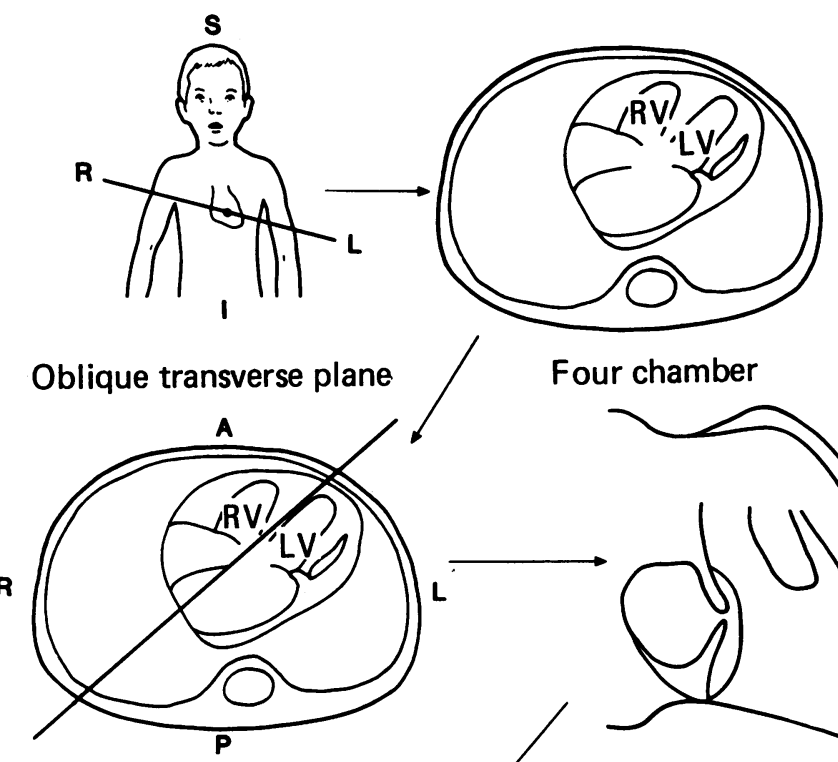

Oblique coronal plane

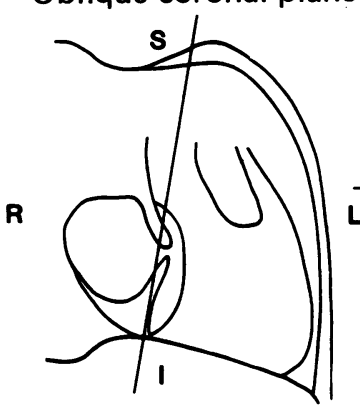

Oblique sagittal plane
Four chamber
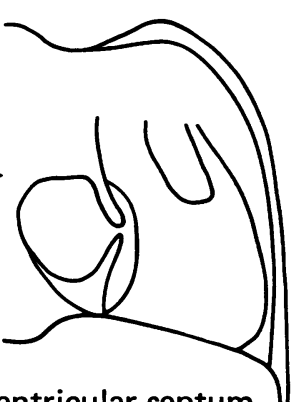

Ventricular septum

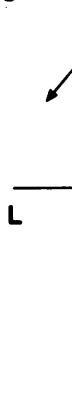

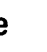

Figure 1 Frequently used imaging planes. Sections from an oblique transverse imaging plane produce a four chamber view. Sections directed along the plane of the ventricular septum (oblique coronal) give a face on view of the outline of the ventricular septum. From this view, a plane through the atrioventricular valve (oblique sagittal) produces a short axis view.

corrective surgery and three patients have been treated palliatively with modified BlalockTaussig shunts. Three patients who were not suitable for early corrective surgery died. One patient undergoing corrective surgery also died in the early postoperative period. Three of these patients underwent a postmortem examination.

\section{METHODS}

Images were obtained with a $1.5 \mathrm{~T}$, whole body, imaging system (Philips Gyroscan). Infants and smaller children were positioned inside a standard $32 \mathrm{~cm}$ proton head coil. All were sedated with chloral hydrate $(50-75 \mathrm{mg} /$ $\mathrm{kg}$ ). Simultaneous sections, $5 \mathrm{~mm}$ thick, separated by $0.5 \mathrm{~mm}$ and gated to the patients electrocardiogram, were acquired using a T1 weighted spin echo sequence with an echo time of $30 \mathrm{~ms}$. Although the size of the matrix was $256 \times 256$, only 180 signals were used to construct the final image; so that the scanning times could be shortened with only a slight reduction in resolution of the images. The field of view was $200-250 \mathrm{~mm}$. With two signal averages being performed for each examina-

tion, the typical scanning time for a series of seven sections was approximately 6 minutes.

Sections were acquired in orthogonal and oblique imaging planes, selected in each case by a cardiologist who was already familiar with the echocardiographic findings in the individual patient. Frequently used planes (fig 1 ) included an oblique transverse section, rotated around an anterior-posterior axis, to give a four chamber view; an oblique coronal plane, rotated around an inferior-superior axis, directed along the plane of the ventricular septum to provide a unique view of the inlet and trabecular portions of the ventricular septum face on; and an oblique sagittal plane, rotated around an inferior-superior axis as well as an anteriorposterior axis, to provide a short axis view of the ventricles and atrioventricular valve. The angles selected to obtain the oblique imaging planes were determined from the structures displayed in pre-existing images and they were varied to suit the anatomy of individual patients. The total scanning time for the complete examination was less than 90 minutes in every patient.

\section{ANATOMICAL SPECIMENS}

We dissected hearts from those patients who died in our series and specimens selected from the cardiopathological museum of the National Heart and Lung Institute to display the anatomy as it would be seen in cross section from imaging planes used by magnetic resonance imaging.

\section{Results}

There were no technical problems with this imaging protocol. Oral sedation proved effective in all cases and respiratory depression was not encountered. All the images were of diagnostic quality. The diagnosis of atrioventricular septal defect was most readily made from sections taken in a transverse plane. In patients with a common atrioventricular orifice both the atrial and ventricular components of the defect were identified. The presence of the common valve was detected by seeing that bridging leaflets were all at one level. The demonstration of both ventricles within a single image enabled their relative dimensions to be assessed (figs 24). In two patients who had separate right and left atrioventricular valve orifices we saw no ventricular component from this view (fig 3).

\section{ATRIAL SEPTUM}

No atrial septum was identified in the three patients with isomerism of the right atrial appendages. In the remaining nine patients, the atrial septum was shown in images taken in various planes. The oblique transverse plane was of greatest use in identifying the presence and size of the atrial component of the defect (figs 2, 5, and 6). We did not find bridging leaflets attached to the atrial septum, confining the anatomical potential for shunting at the ventricular level, in any of our patients. The four chamber view showed the characteristic "drum stick" appearance of the atrial septum 

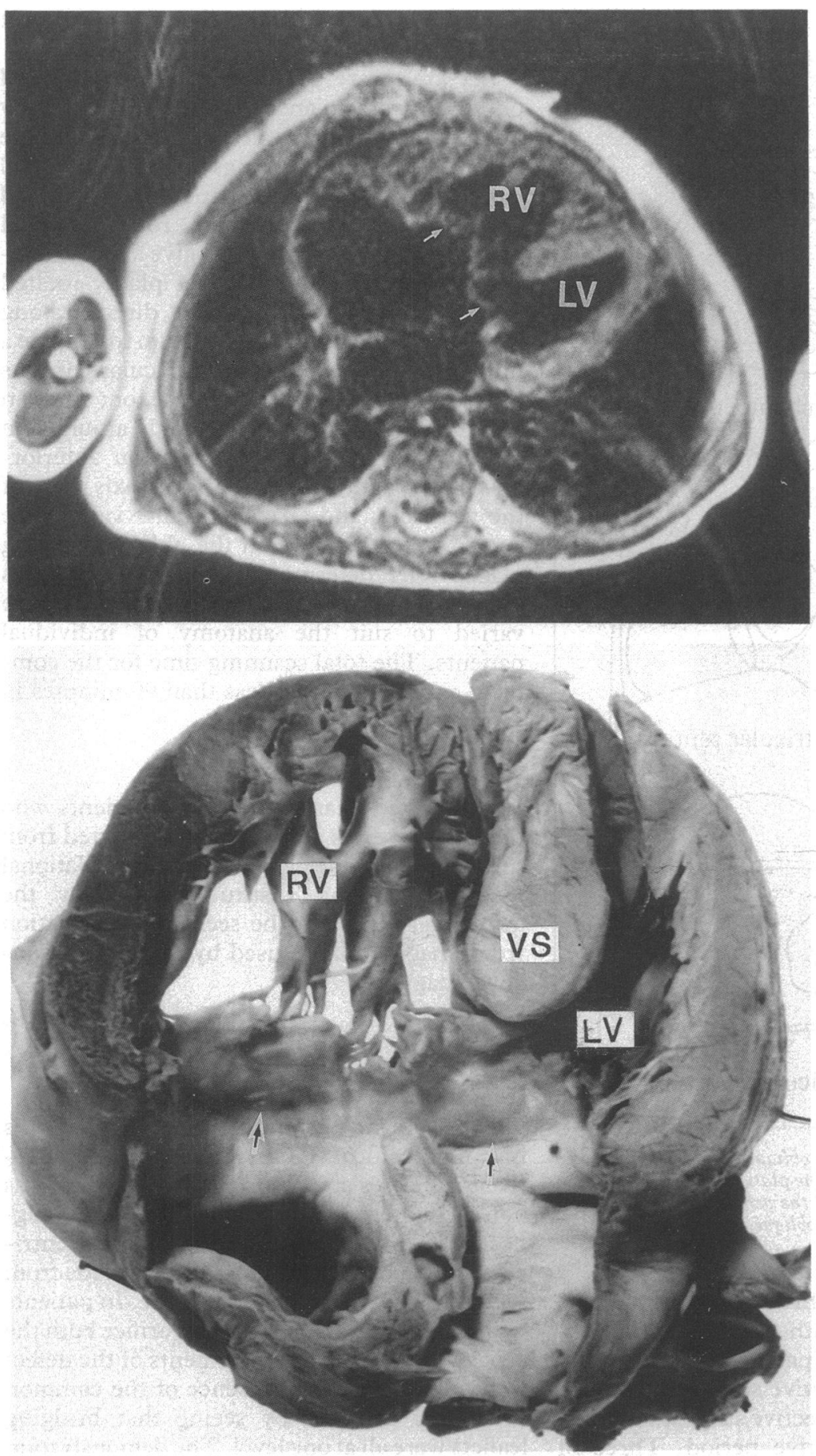

Figure 2 (Above) A section taken in an oblique transverse imaging plane from a patient (case 3) with atrioventricular septal defect and common valvar orifice. Both components of the defect are shown and the atrioventricular valves are at a common level (arrows). Relative ventricular dimensions can also be assessed from this view. RV, right ventricle; $L V$, left ventricle. (Below) $A$ postmortem specimen from a different patient with atrioventricular septal defect and common valvar orifice, cut to show a four chamber view for comparison with the magnetic resonance imaging section. $R V$, right ventricle; $L V$, left ventricle; $V S$, ventricular septum; arrows = atrioventricular valve.

that is associated with an atrial component of the defect (fig 5).

VENTRICULAR SEPTUM

Because the ventricular septum is a three dimensional structure it was not possible to encompass it all within one single image. The use of serial sections in several planes enabled all its portions to be visualised. Images from transverse planes showed the muscular inlet, trabecular portions, and outlet portions (figs 2 and 3). An oblique coronal plane showed the scooped out muscular inlet portion, the muscular trabecular portion, and the outlet septum (figs 7-9). By using a combination of these views we could see the size of the ventricular component of the defect, if present, in every case, and correspondingly document its absence.

Because the heart lies obliquely within the thorax, the use of standard transverse planes often produced foreshortened views of the ventricle, the ventricular septum, and the ventricular component of the defect. In such cases, it was important to view sections in an oblique transverse plane (fig 1). Although images from this plane showed the ventricular component of the defect, it was often impossible to assess its size because attachments of the bridging leaflets to the ventricular septum obscured the defect (figs 6 and 10). Images taken from the oblique coronal plane directed along the ventricular septum, however, gave a unique view of its inlet and trabecular portions, which were seen face on. The ventricular component was identified from this view, appearing as a scooped out defect within the overall septum (figs 7 and 8) whose size was readily appreciated. Any sections that were inadvertently directed obliquely through the defect cut obliquely through the ventricular septum and failed to show the defect adequately. A repeat scan at a slightly different angulation ensured true alignment through the defect.

This view also showed the presence of attachments of the superior and inferior bridging leaflets to the crest of the ventricular septum (figs 7 and 8). In those patients with separate right and left atrioventricular valvar orifices the bridging leaflets of the valve and their connecting tongue were seen closely attached to the ventricular septum (fig 9), thus completely obliterating the ventricular component of the defect. Both the magnetic resonance image and the anatomical specimen in fig 9 show that there was no ventricular component to the defect. But you can still see that the scooped-out defect has the same dimensions as seen in patients with common valvar orifice (figs 7 and 8) although the anatomical potential for left-to-right shunting is entirely through the atrial component of the defect when the leaflets are firmly attached to the crest of the ventricular septum.

\section{ATRIOVENTRICULAR VALVE}

By using various imaging planes we saw and identified the superior and inferior bridging leaflets, together with their attachments to the ventricular septum. From a series of images taken in an oblique transverse plane, we found that the lowermost sections would include the inferior bridging leaflet while more cranial sections would include the superior bridging leaflet (fig 10). Images from an oblique coronal plane directed along the ventricular septum showed both the bridging leaflets together (figs 7 and 8 ).

We attempted to show the atrioventricular valve in the short axis view in oblique sagittal imaging planes. The results were universally disappointing. In only one patient was it pos- 


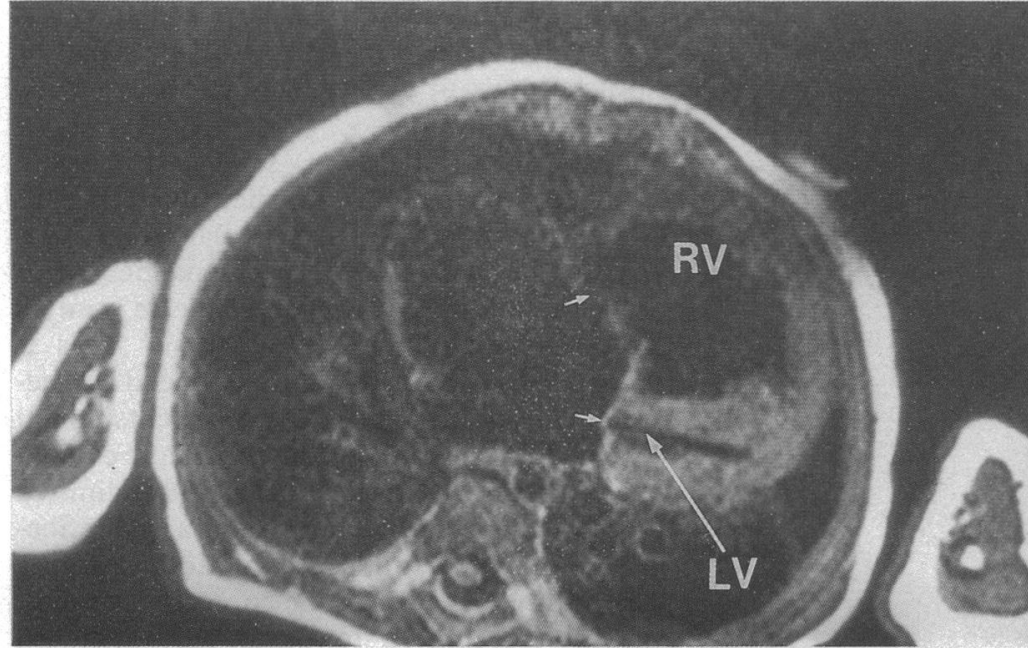

Figure 3 Four chamber view taken during early systole from patient 5 with an atrioventricular septal defect and separate right and left valve orifices. There was ventricular disproportion with hypoplasia of the morphologically left ventricle. The atrioventricular valves were inserted at the same level (arrows). No ventricular component of the defect was visible. $R V$, right ventricle, $L V$, left ventricle.
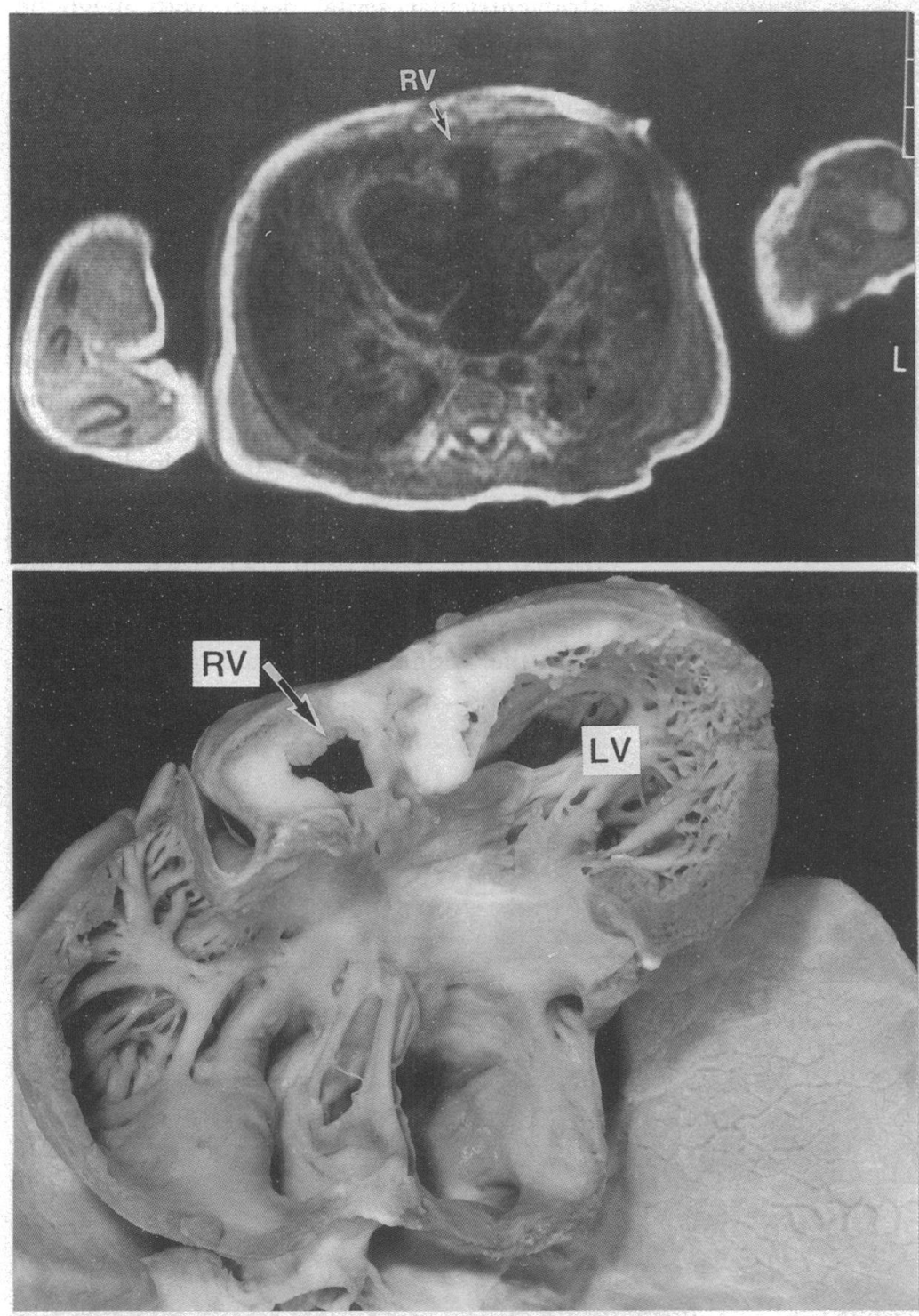

Figure 4 (Above) Transverse plane giving a four chamber view showing ventricular disproportion with a hypoplastic morphologically right ventricle $(R V)$ in patient 12. Compare with figures 2 and 3. (Below) Anatomical specimen from the same patient showing hypoplastic morphologically right ventricle. $R V$, right ventricle; $L V$, left ventricle. sible to see leaflets other than bridging leaflets. It was not possible in this plane to determine whether there was a common orifice or two separate atrioventricular valvar orifices. Papillary mucles within the left ventricle, however, were seen in this view. These were shown to have the superior-inferior relation known to be typical for this malformation (fig 11). Their distal insertions were not identified.

\section{VENTRICULAR DIMENSIONS}

The relative ventricular dimensions were assessed accurately in all patients. Oblique transverse imaging planes showed both ventricles side by side in long axis (figs 3, 4, and 6) and oblique sagittal imaging planes showed both ventricles together in an anterior-posterior relation in short axis (figs 11 and 12). Considerable ventricular hypoplasia of the morphologically left ventricle (figs 3 and 12) was shown in one patient and of the morphologically right ventricle in another (fig 4).

\section{CORRELATION WITH ADDITIONAL}

INVESTIGATIONS

Six of the 12 patients have undergone corrective surgery. One patient died in the early postoperative period after corrective surgery. A late death occurred in a patient with hypoplastic pulmonary arteries who underwent palliative surgery. Two patients died without operation being performed. Necropsies were performed on three of the four patients who died. In all these cases, the accuracy of the findings at magnetic resonance imaging was confirmed. There were no major disagreements with the angiographic or echocardiographic findings (table). Magnetic resonance imaging was better than both echocardiography and angiography at showing the relative ventricular dimensions. In one patient hypoplasia of the morphologically left ventricle, correctly predicted with magnetic resonance imaging, was not fully appreciated with either of the other imaging techniques. Echocardiographic and angiographic assessment of the size of the ventricular component of the defect was made difficult in some patients because attachments of bridging leaflets to the ventricular septum often obscured the defect. Magnetic resonance imaging accurately showed the size of the defect in these cases through use of the oblique coronal plane which imaged the ventricular septum face on. Magnetic resonance imaging, however, was not good at identifying valvar leaflets other than the bridging ones and was not able consistently to show the distal insertion of the papillary muscles.

\section{Discussion}

Magnetic resonance imaging is particularly suited to the examination of congenital heart malformations. ${ }^{4-6}$ It is non-invasive and does not require the use of ionising radiation. With appropriate imaging procedures, moving blood does not produce any signal. This means that high resolution images of vascular structures can be achieved without the use of contrast 


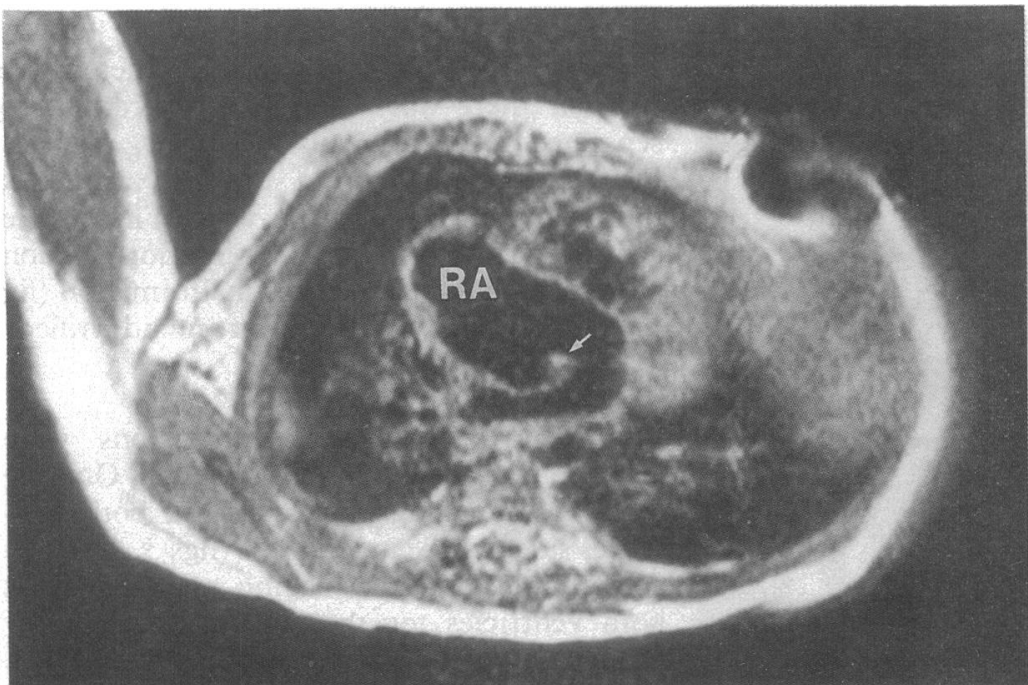

Figure 5 Section taken in a transverse imaging plane in patient 2 showing an atrial septum with the characteristic "drum stick" appearance associated with this defect (arrow). Note that the right atrium $(R A)$ is larger than the left.

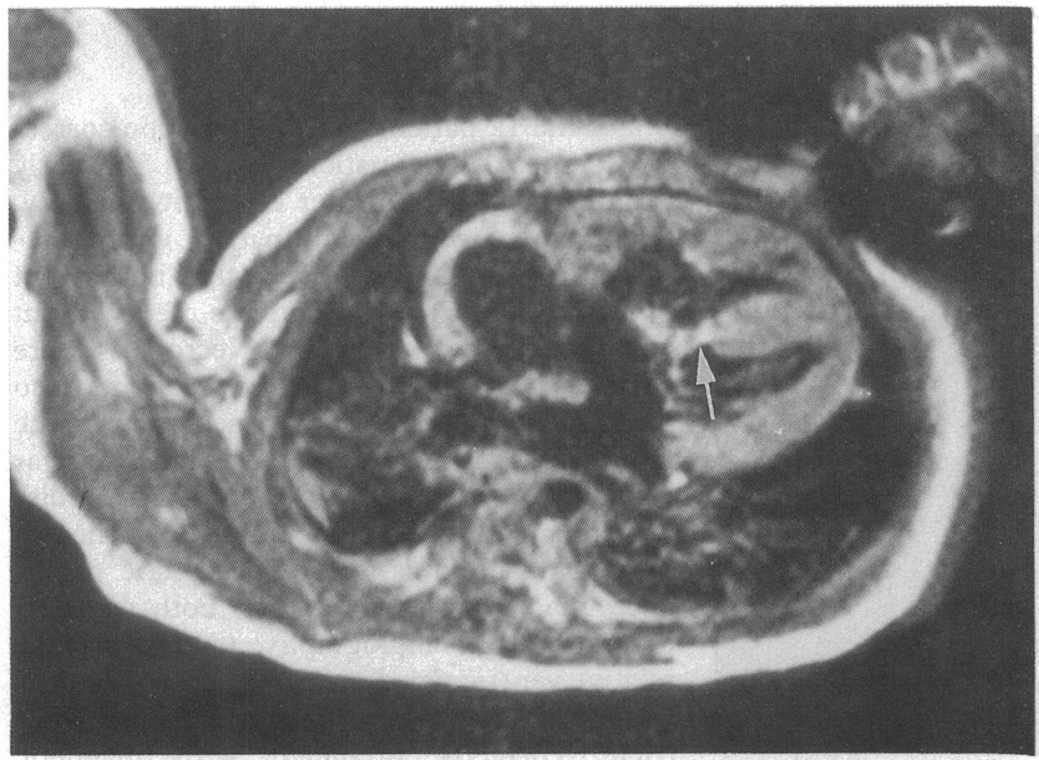

Figure 6 Patient 7 had a common atrioventricular orifice with a ventricular component. The size of the ventricular component, however, was not apparent from this four chamber view because it was obscured by dense attachments of the bridging leaflets to the crest of the ventricular septum (arrow). agents. In addition, the image signal is not affected by the depth of structures within the thoracic cavity or by the presence of overlying bone or lung.

Our study differs in several important aspects from some of the earlier investigations of patients with atrioventricular septal defects. ${ }^{7-9}$ First, because we used a magnet with a higher field strength we were able to study a group of much younger patients. ${ }^{10}$ This is important because many patients need corrective operation in infancy. Such patients do not always require invasive haemodynamic evaluation. Preoperative investigation is often limited to cross sectional echocardiography. ${ }^{3}$ Secondly, we made full use of oblique imaging planes. This was not done in earlier studies, which were limited to using only standard orthogonal planes..$^{7-9}$ Thirdly, we attempted to identify areas in which magnetic resonance imaging has advantages over existing imaging techniques and which can provide information of practical importance in construction of protocols for management.

Although it is straightforward to diagnose atrioventricular septal defect with magnetic resonance imaging (predominantly from a four chamber view, where the septal deficiency is readily seen), this feature alone is unlikely to be of any great practical use because in most patients the diagnosis will already have been achieved non-invasively with cross sectional echocardiography. The importance of magnetic resonance imaging, therefore, is likely to lie in the ability and accuracy in which it can identify anatomical features that are relevant to operation. It is often difficult to estimate with cross sectional echocardiography the size of the ventricular component of the defect, if present. In some cases, problems can arise in distinguishing between an atrioventricular septal defect with common valvar orifice and a small ventricular component from a defect with separate orifices and no potential for ventricular shunting ${ }^{11}$ - that is when dense attachments between the bridging leaflets and the crest of the
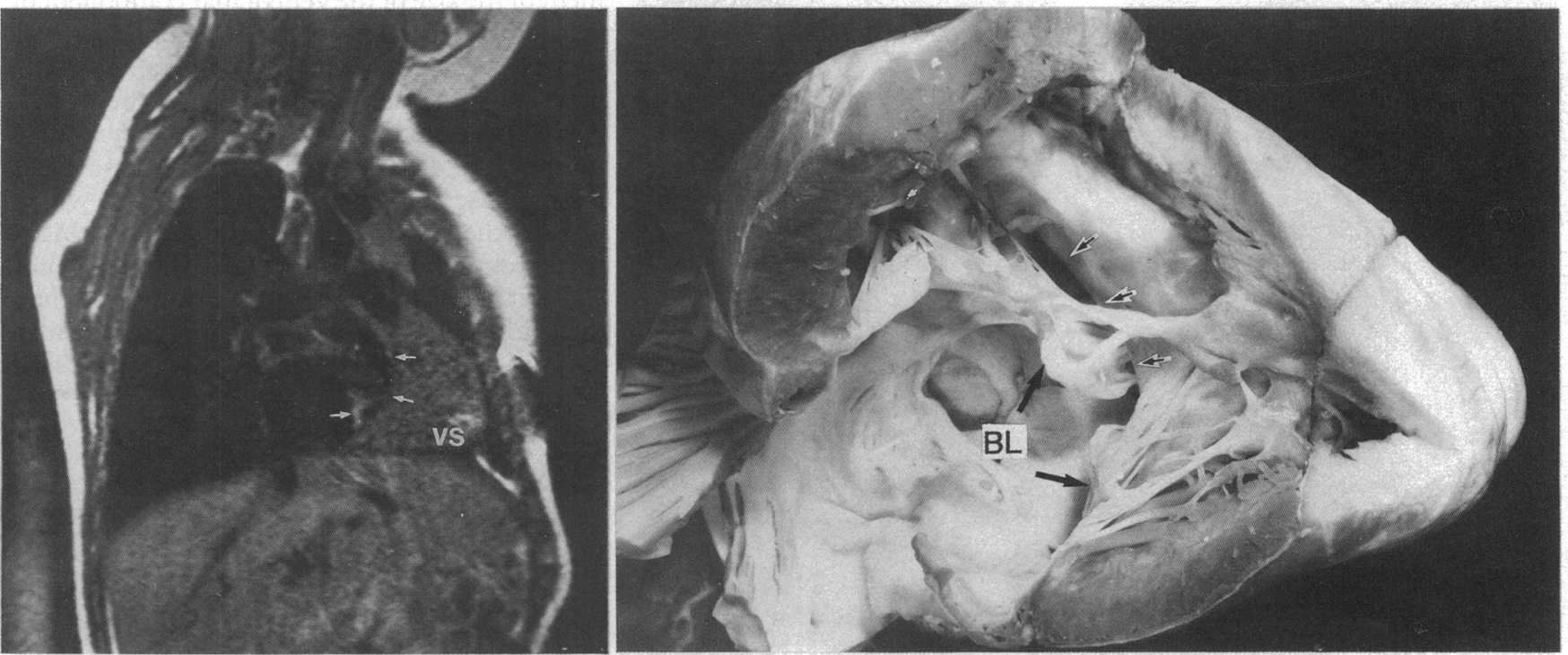

Figure 7 (Left) Oblique coronal section showing the ventricular septum (VS) face on and the scooped out appearance of the ventricular component of the defect (arrows) in patient 11. The inferior bridging leaflet was seen with attachments to the crest of the ventricular septum (single arrow). (Right) Anatomical specimen from the same patient. The ventricular component of the defect was seen (arrows) as well as bridging leaflets (BL) with attachments to the crest of the ventricular septum. 

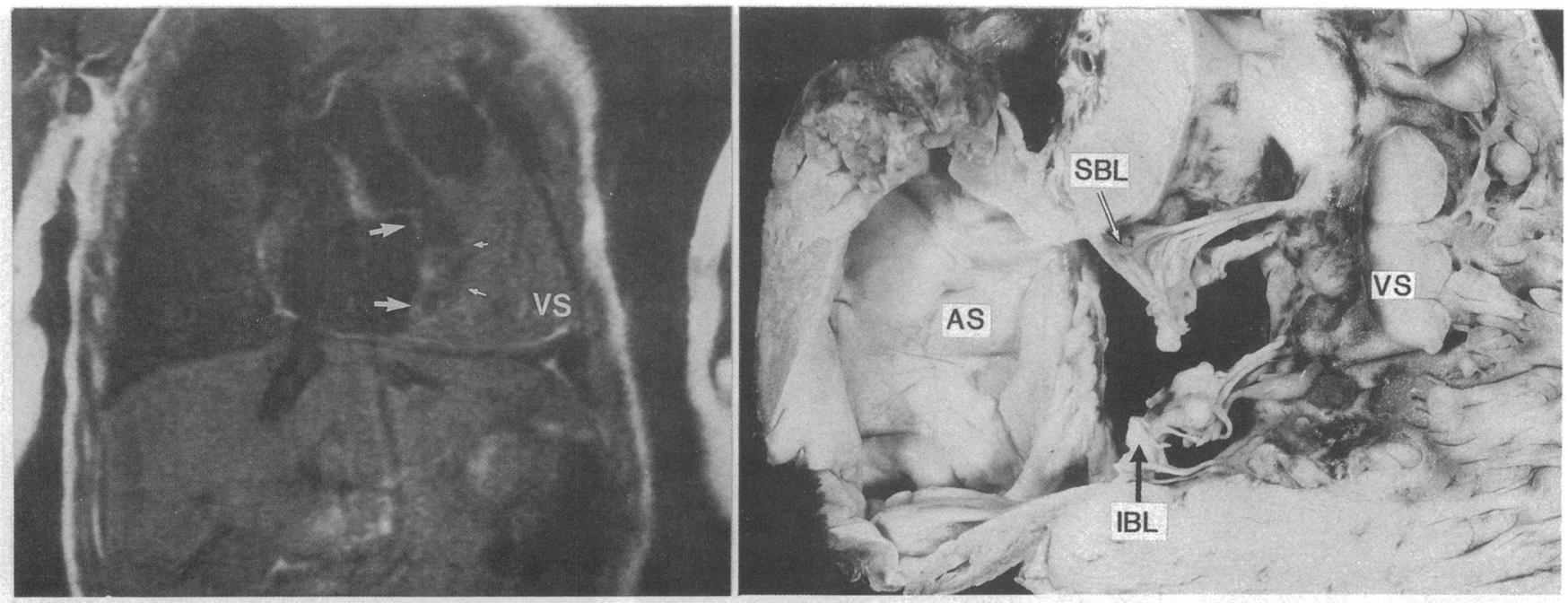

Figure 8 (Left) Section in an oblique coronal imaging plane from a patient (case 6) with atrioventricular septal defect and common valvar orifice. The ventricular septum (VS) was shown face on and free floating bridging leaflets (large arrows) were seen with attachments to the right ventricular aspect of the ventricular septum (small arrows). (Right) Postmortem specimen from a different patient cut in the same plane, demonstrating the anatomy shown in the magnetic resonance imaging section. SBL, superior bridging leaflet; IBL, inferior bridging leaflet; VS, ventricular septum, $A S$, atrial septum.
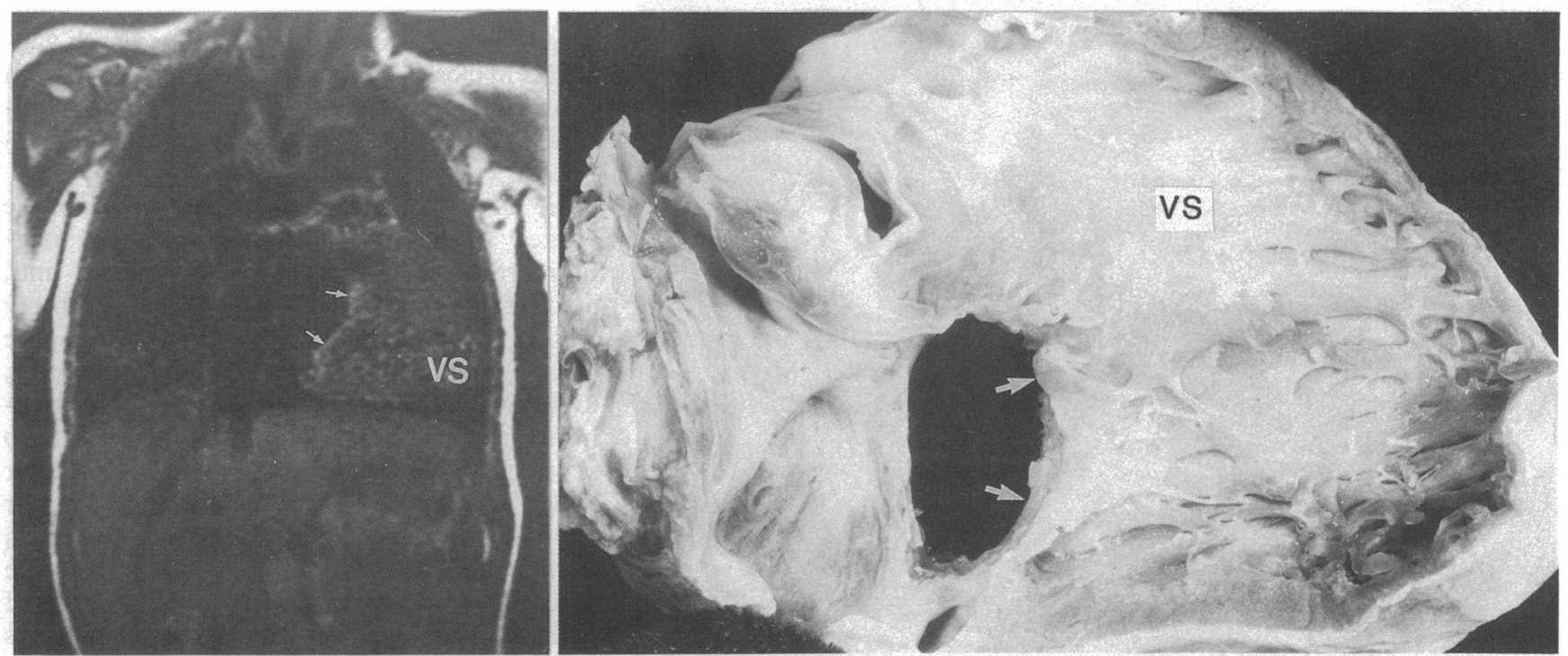

Figure 9. (Left) Oblique coronal section from patient 5. The bridging leaflets (arrows) can be seen closely attached to the ventricular septum (VS) obliterating the ventricular component of the defect. Compare with figures 7 and 8. (Right) Postmortem specimen from a different patient with separate right and left atrioventricular valve orifices, cut in a similar plane to compare with the magnetic resonance imaging findings. The bridging leaflets (arrows) are seen closely attached to the ventricular septum (VS).

ventricular septum obscure the ventricular component of the defect. Invasive investigations may then be necessary to make a decision on the timing of surgery. ${ }^{3}$ Even with angiography, it can be difficult to differentiate between these defects. ${ }^{12}$ The oblique coronal plane, which images the ventricular septum face on, is unique to magnetic resonance imaging. It is not possible with echocardiography or angiography (which is an imaging technique using projections rather than sections). As we showed, this view clearly outlined the component of the defect scooped from the ventricular septum. It also shows both bridging leaflets and identifies the degree of their attachments to the scooped out septum. In our two patients with separate valvar orifices and no ventricular component, it showed close approximation of the bridging leaflets to the crest of the ven- tricular septum with complete obliteration of the ventricular component. In all patients studied, magnetic resonance imaging was the most accurate imaging technique for assessing the presence and size of the ventricular component of the defect.

Another strength of magnetic resonance imaging is its ability to display cardiac structures in relation to the rest of the thoracic cavity. This allowed the chamber dimensions to be assessed immediately, enabling patients with atrial and, more importantly, ventricular disproportion to be identified. This observation is important because one determinant of surgical risk is the presence of ventricular hypoplasia. ${ }^{213}$ Although this is relatively common it may be difficult to detect with echocardiography ${ }^{14}$ and, indeed, angiography, as was the case in one patient of our series. Because 

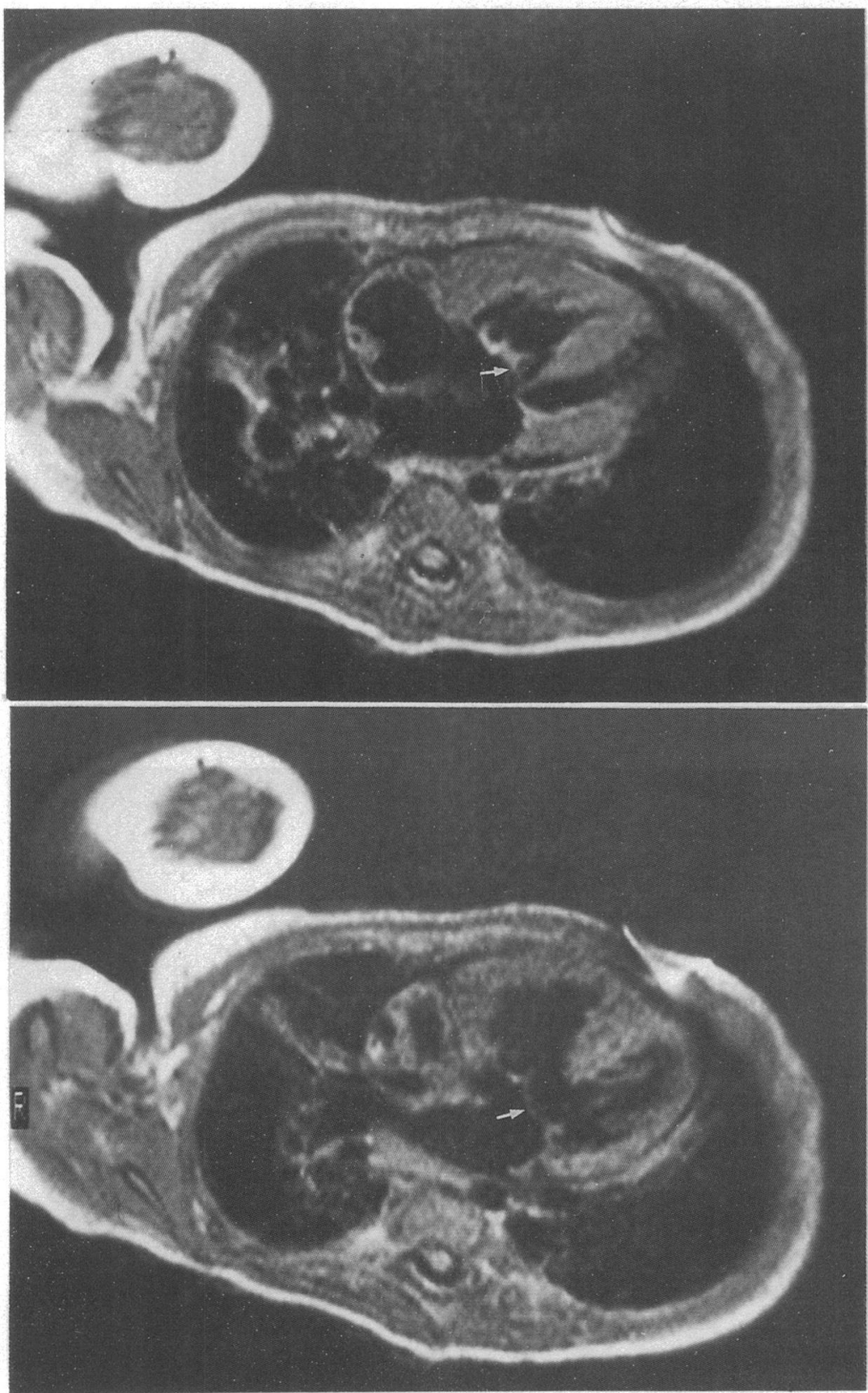

Figure 10 (Above) Transverse section from a patient with a common atrioventricular orifice showing inferior bridging leaflet (arrow) with attachments to the ventricular septum in patient 6. The ventricular component of the defect was not seen clearly.

(Below) A more cranially directed section from the same patient. The superior bridging leaflet was free floating (arrow) and the ventricular component of the defect was visible.

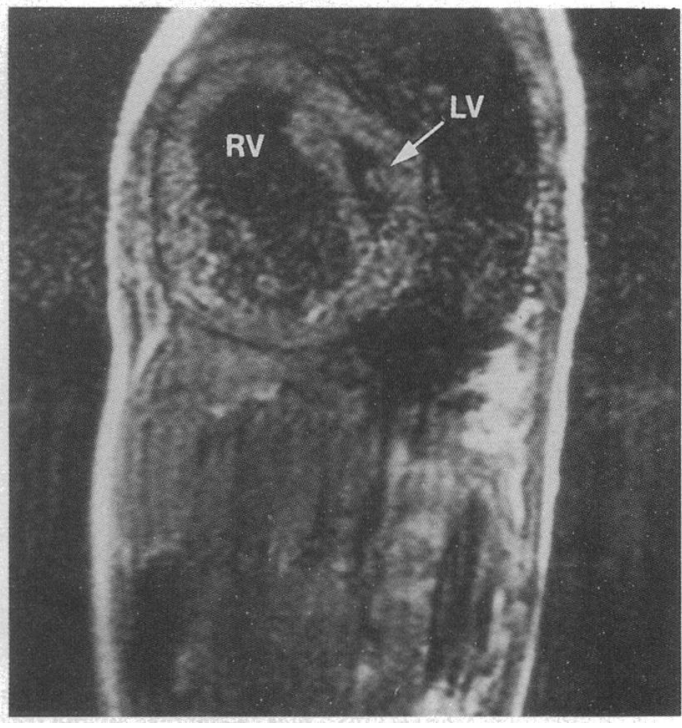

Figure 12 An oblique sagittal section showing both ventricles in short axis (patient 5). There was hypoplasia of the morphologically left ventricle. Compare with figure 10. $R V$, right ventricle; $L V$, left ventricle.

magnetic resonance imaging showed both ventricles in close relation to each other and in both short and long axis views, ventricular hypoplasia, when present, was more easily diagnosed.

In all of the patients who had corrective surgery or necropsy, the accuracy of the magnetic resonance images was confirmed and, apart from the areas previously discussed, there was good correlation with echocardiographic and angiographic findings. We have, however, identified some potential weaknesses of magnetic resonance imaging, including a failure to show clearly all leaflets of the atrioventricular valve and to show the insertions of their papillary muscles. Our current experience, therefore, suggests that magnetic resonance imaging can be of value in the management of patients with atrioventricular septal defects when cross sectional echocardiography is the only imaging technique used for evaluation before operation and where the cross sectional echocardiographic findings or the angiographic findings are in dispute. In such cases magnetic
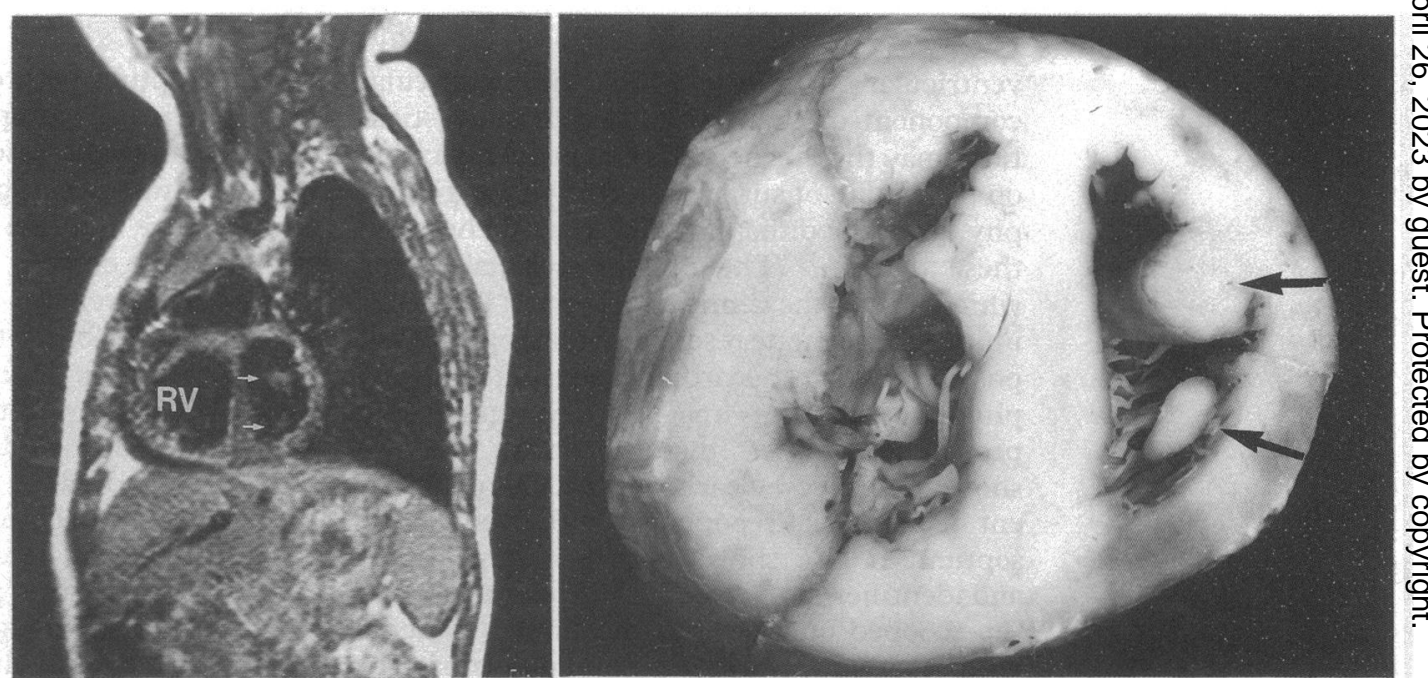

Figure 11 (Left) Oblique sagittal plane showing both ventricles in short axis in patient 11. The characteristic superior-inferior relation of papillary muscles (arrows) associated with atrioventricular septal defect was visible within the morphologically left ventricle. RV, right ventricle. (Right) Anatomical specimen from this patient cut in a similar plane. The superior-inferior relation of the papillary muscles (arrows) was visible within the morphologically left ventricle. 
Patient details

\begin{tabular}{|c|c|c|c|c|c|c|c|}
\hline $\begin{array}{l}\text { Case } \\
\text { No }\end{array}$ & Age & $\begin{array}{l}\text { Valvar } \\
\text { morphology }\end{array}$ & Echo & Angio & Surgery & Necropsy & $M R I$ findings \\
\hline $\begin{array}{l}1 \\
2 \\
3 \\
4 \\
5\end{array}$ & $\begin{array}{c}2 \text { wk } \\
2 \text { wk } \\
14 \text { mnth } \\
9 \text { days } \\
10 \text { mnth }\end{array}$ & $\begin{array}{l}\text { Common } \\
\text { Common } \\
\text { Common } \\
\text { Common } \\
\text { Separate }\end{array}$ & $\begin{array}{l}+ \\
+ \\
+ \\
+ \\
+\end{array}$ & $\begin{array}{l}+ \\
+ \\
+ \\
+\end{array}$ & $\begin{array}{l}+ \\
+ \\
+\end{array}$ & + & $\begin{array}{l}\text { Agreed } \\
\text { Agreed } \\
\text { Agreed } \\
\text { Agreed } \\
\text { Hypoplastic left } \\
\text { ventricle }\end{array}$ \\
\hline $\begin{array}{r}6 \\
7 \\
8 \\
9 \\
10 \\
11 \\
12\end{array}$ & $\begin{array}{l}4 \text { mnth } \\
14 \text { mnth } \\
2 \text { wk } \\
18 \text { mnth } \\
22 \text { mnth } \\
6 \text { wk } \\
1 \text { wk }\end{array}$ & $\begin{array}{l}\text { Common } \\
\text { Common } \\
\text { Common } \\
\text { Common } \\
\text { Separate } \\
\text { Common } \\
\text { Common }\end{array}$ & $\begin{array}{l}+ \\
+ \\
+ \\
+ \\
+ \\
+ \\
+\end{array}$ & $\begin{array}{l}+ \\
+ \\
+ \\
+\end{array}$ & $\begin{array}{l}+ \\
+ \\
+\end{array}$ & $\begin{array}{l}+ \\
+\end{array}$ & $\begin{array}{l}\text { Agreed } \\
\text { Agreed } \\
\text { Agreed } \\
\text { Agreed } \\
\text { Agreed } \\
\text { Agreed } \\
\text { Hypoplastic right } \\
\text { ventricle }\end{array}$ \\
\hline
\end{tabular}

MRI, magnetic resonance imaging.
2 Studer M, Blackstone EH, Kirklin JW, et al. Determinants of early and late results of repair of atrioventricular septal
(canal) defects. J Thorac Cardiovasc Surg 1982;84: (canal) defects. J Thorac Cardiovasc Surg 1982;84: $523-42$.

3 Kirklin JW, Barret-Boyes BG. Cardiac surgery. New York: Wiley Medical, 1986:561.

4 Baker EJ, Ayton V, Smith MA, et al. Magnetic resonance imaging of coarctation of the aorta in infants: use of a high field strength. Br Heart $J$ 1989;62:97-101.

5 Baker EJ, Ayton V, Smith MA, et al. Magnetic resonance imaging at a high field strength of ventricular septal defects in infants. Br Heart $J 1989 ; 62: 305-10$.

6 Higgins CB, Byrd BF, Farmer DW, Osaki L, Silverman NH, Cheitlin MD. Magnetic resonance imaging in patients with congenital heart disease. Circulation patients with $1984 ; 70: 851-60$.

7 Fletcher BD, Jacobstein MD, Nelson AD, Riemenschneider TA, Alfidi RJ. Gated magnetic resonance imaging of TA, Alfidi RJ. Gated magnetic resonance imaging of congenital

8 Jacobstein MD, Fletcher BD, Goldstein S, Riemender TA. Evaluation of atrioventricular septal defect by magnetic resonance imaging. Am J Cardiol 1985;55:1158-61.

9 Didier D, Higgins CB, Fischer MR, Osaki L, Silverman NH, Cheitlin MD. Congenital heart disease: gated MR imaging in 72 patients. Radiology 1986;158:227-35.

resonance imaging can complement morphological information obtained earlier and so improve diagnostic accuracy.

We thank the British Heart Foundation, the Joseph Levy Foundation, Sir Philip and Lady Harris, the Special Trustees of Guy's Hospital, and Philips Medical Systems for help in funding this project.

1 Anderson RH, Macartney FJ, Shinebourne EA, Tynan M. Paediatric cardiology. Edinburgh: Churchill Livingstone, 1987:574-6.
10 Smith MA, Baker EJ, Ayton V, Parsons JM, Ladusans EJ, Maisey MN. Magnetic resonance imaging of the infant heart at 1.5 T. Br J Radiol 1989;62:367-70.

11 Smallhorn JF, Tommasini G, Anderson RH, Macartney FJ. Assessment of atrioventricular septal defect by two dimensional echocardiography. Br Heart $J$ 1982;47: 109-21.

12 Macartney FJ, Rees PG, Daly K, et al. Angiocardiographic appearances of atrioventricular defects with particular reference to distinction of ostium primum atrial septal defect from common atrioventricular orifice. Br Heart J
1979;42:640-56.

13 Kirklin JW, Barret-Boyes BG. Cardiac surgery. New York: Wiley Medical, 1986:579-83.

14 Mehta S, Hirschfeld S, Riggs T, Liebman J. Echocardiographic estimation of ventricular hypoplasia in complete atrioventricular canal. Circulation 1979;59:888-93. 